\title{
HLA antigens in chronic inflammatory demyelinating polyneuropathy
}

\author{
D J Feeney, J D Pollard, J G McLeod, G J Stewart, T J Doran
}

\begin{abstract}
HLA typing of 71 patients with chronic inflammatory demyelinating polyneuropathy (CIDP) showed an overall increase in frequencies of HLA-A3, -B7, -DR2 as well as concomitantly decreased frequencies of HLA-44 and DR7. The strongest associations were seen with HLA-DR2, -DR7 and -B44 in CIDP overall, although they did not reach statistical significance.
\end{abstract}

It is generally considered that acute inflammatory neuropathy (Guillain-Barré syndrome, GBS) and chronic inflammatory neuropathy (CIDP) are variants of the same disease ${ }^{1-4}$ and it has been proposed that genetically determined host factors may govern the chronicity of the pathological process. ${ }^{4-6}$ The hypothesis has received some support from the reported association of HLA-B8, -Dw3, ${ }^{56}-\mathrm{AW} 30$ and -AW31 antigens ${ }^{5}$ with CIDP. By contrast no association of GBS has been demonstrated with HLA antigens. ${ }^{7-8}$ Further evidence for genetic factors in the pathogenesis of CIDP include the demonstration of an association with the M3 allele of the alpha-1-antitrypsin system $(\mathrm{PiM} 3)^{9}$ and possibly $\mathrm{Gm}$ haplotypes ${ }^{10}$ on chromosome 14

As the earlier studies of HLA antigens and CIDP were performed on small numbers of patients, we have examined the HLA class I and II antigen frequencies on a larger group of 71 patients.

Department of Medicine, University of Sydney, Sydney DJ Feeney JD Pollard

JG McLeod

Department of Medicine, Westmead Hospital, Westmead GJ Stewart

Red Cross Blood Transfusion Service, Sydney, New South Wales, Australia TJ Doran

Correspondence to: JG McLeod, Bushell Professor of Neurology, The Department of Medicine, University of Sydney, Sydney, New South Wales 2006, Australia.

Received 2 August 1989 Accepted 26 September 1989

\section{Patients and methods}

HLA-A and -B antigens were determined in 71 patients who satisfied the diagnostic criteria for CIDP. ${ }^{4,11,12}$ Fifty six of these were also investigated for HLA-DR /-DRw and -DQ. CIDP patients were further divided into chronic relapsing (CR) and non-relapsing (CNR) subgroups. ${ }^{12}$ Most of the patients have been described earlier ${ }^{4,12}$ and this study includes those reported in the earlier, smaller series. ${ }^{5}$

Control populations consisted of 2,516 normal healthy blood donors and hospital staff typed for HLA-A and -B locus antigens. One thousand and fifty eight of these were also typed for HLA-D. Three hundred and fifteen and 322 were satisfactorily typed for DRw and DQ respectively.
Typing for HLA-A and -B antigens was carried out by the standard NIH microlymphocytotoxicity test. HLA-DR/DRw/DQ antigens were typed by the standard procedure of the Seventh International Histocompatibility workshop. All typing sera were standardised against International Histocompatibility Workshop sera. Phenotype frequencies were compared by the chi-square test using Yates' correction factor for continuity. Correction for multiple comparisons was applied where appropriate.

\section{Results}

Results are summarised in tables 1-3.

HLA typing revealed non-significant frequency increases of HLA-A3 ( $p=0.239$ ) -B7 $(\mathrm{p}=0.150),-D R 2(\mathrm{p}=0.104)$ and an overall decrease of $-\mathrm{B} 44(\mathrm{~B} 12)(\mathrm{p}=0.069)$ and -DR7 ( $p=0.060)$ frequencies in both chronic relapsing (CR) and non-relapsing (CNR) subgroups of CIDP. No change was seen in the frequencies of HLA-A30/31 or -B8 in either group. The frequency of HLA-DR2 was raised in both subgroups although it fell short of statistical significance $(p=0 \cdot 104)$.

It is well recognised that HLA-B7 and -DR2 are in linkage disequilibrium in the normal population. We have observed a non statistically significant increase in the frequency of HLA-B7 and -DR2 in this patient cohort and would therefore expect a corresponding increase in the co-incidence of the B7-DR2 supratype. In the current data, this cooccurrence of B7 and DR2 appears to be much greater than would be seen normally (table 3 ).

\section{Discussion}

This report represents the largest number of patients so far studied for HLA associations in CIDP. It does not confirm earlier observations of a borderline increase in frequency of HLA$\mathrm{B} 8 /-\mathrm{Dw} 3$ or $-\mathrm{Aw} 30 / 31 .{ }^{5,6}$ This work suggests that there may be an association with -DR2, although the findings do not reach statistical significance after applying the correction for multiple comparisons and would need to be confirmed in another cohort. The difference between our findings and those of the earlier studies are probably explained by the smaller number of patients in the first reports.

Since CIDP has been regarded as the peri- 
Table 1 Antigen frequencies

\begin{tabular}{|c|c|c|c|c|}
\hline $\begin{array}{l}\text { HLA-A Locus } \\
\text { Antigen }\end{array}$ & CIDP Total & $C I D P-C R$ & $C I D P-C N R$ & Controls \\
\hline $\begin{array}{l}\text { A1 } \\
\text { A2 } \\
\text { A3 } \\
\text { A11 } \\
\text { A23(9) } \\
\text { A24(9) } \\
\text { A26(10) } \\
\text { A28 } \\
\text { A29(19) } \\
\text { A30(19) } \\
\text { A31(19) } \\
\text { A32(19) } \\
\text { Aw33(19) } \\
\text { Aw34(10) } \\
\text { Aw36 } \\
\text { Aw43 }\end{array}$ & $\begin{array}{l}0 \cdot 3622 \\
0.4507 \\
0.3380^{a} \\
0 \cdot 1127 \\
0.0000 \\
0 \cdot 2113 \\
0.0425 \\
0.0425 \\
0.0563 \\
0.0704 \\
0 \cdot 0425 \\
0.0563 \\
0.0000 \\
0.0000 \\
0.0000 \\
0.0000 \\
\mathrm{n}=71\end{array}$ & $\begin{array}{l}0.3542 \\
0.4583 \\
0.3333 \\
0.1250 \\
0.0000 \\
0.2083 \\
0.0208 \\
0.0208 \\
0.0832 \\
0.0832 \\
0.0208 \\
0.0624 \\
0.0000 \\
0.0000 \\
0.0000 \\
0.0000 \\
\mathrm{n}=48\end{array}$ & $\begin{array}{l}0.3913 \\
0.4348 \\
0.3478 \\
0.0870 \\
0.0000 \\
0.2174 \\
0.0870 \\
0.0870 \\
0.0000 \\
0.0435 \\
0.0870 \\
0.0435 \\
0.0000 \\
0.0000 \\
0.0000 \\
0.0000 \\
\mathrm{n}=23\end{array}$ & $\begin{array}{l}0.3373 \\
0.4901 \\
0.2677 \\
0.1269 \\
0.0259 \\
0.1480 \\
0.0601 \\
0.0680 \\
0.0772 \\
0.0434 \\
0.0354 \\
0.0632 \\
0.0115 \\
0.0004 \\
0.0004 \\
0.0000 \\
\mathrm{n}=2516\end{array}$ \\
\hline $\begin{array}{l}\text { HLA-B Locus } \\
\text { Antigen } \\
\text { B7 } \\
\text { B8 } \\
\text { B13 } \\
\text { B14 } \\
\text { B18 } \\
\text { B27 } \\
\text { B35 } \\
\text { B37 } \\
\text { B38(16) } \\
\text { B39(16) } \\
\text { Bw41 } \\
\text { Bw42 } \\
\text { B44(12) } \\
\text { B45(12) } \\
\text { Bw46 } \\
\text { Bw47 } \\
\text { Bw48 } \\
\text { B49(21) } \\
\text { Bw50 } \\
\text { B51(5) } \\
\text { Bw52(5) } \\
\text { Bw53 } \\
\text { Bw54(22) } \\
\text { Bw55(22) } \\
\text { Bw56(22) } \\
\text { Bw57 } \\
\text { Bw58(17) } \\
\text { Bw60(40) } \\
\text { Bw61(40) } \\
\text { Bw62(15) } \\
\text { Bw63 } \\
\text { Bw71(70) } \\
\text { Bw72(70) } \\
\text { Bw73 } \\
\text { Bw }\end{array}$ & $\begin{array}{l}C I D P \text { total } \\
0.3521^{b} \\
0 \cdot 2535 \\
0.0704 \\
0.1408 \\
0.0282 \\
0.0425 \\
0.1408 \\
0.0425 \\
0.0563 \\
0.0000 \\
0.0141 \\
0.0000 \\
0.1833^{c} \\
0.0000 \\
0.0000 \\
0.0000 \\
0.0000 \\
0.0282 \\
0.0000 \\
0.1275 \\
0.0141 \\
0.0141 \\
0.0000 \\
0.0141 \\
0.0141 \\
0.0850 \\
0.0000 \\
0.0991 \\
0.0141 \\
0.1275 \\
0.0000 \\
0.0000 \\
0.0000 \\
0.0000 \\
\mathrm{n}=71\end{array}$ & $\begin{array}{l}C I D P-C R \\
0 \cdot 3333 \\
0 \cdot 2500 \\
0 \cdot 0624 \\
0 \cdot 1664 \\
0 \cdot 0208 \\
0 \cdot 0416 \\
0 \cdot 1040 \\
0 \cdot 0624 \\
0 \cdot 0624 \\
0 \cdot 0000 \\
0 \cdot 0208 \\
0 \cdot 0000 \\
0 \cdot 2083 \\
0 \cdot 0000 \\
0 \cdot 0000 \\
0 \cdot 0000 \\
0 \cdot 0000 \\
0 \cdot 0416 \\
0 \cdot 0000 \\
0 \cdot 1458 \\
0 \cdot 0000 \\
0 \cdot 0208 \\
0 \cdot 0000 \\
0 \cdot 0000 \\
0 \cdot 0000 \\
0 \cdot 1040 \\
0 \cdot 0000 \\
0 \cdot 0624 \\
0 \cdot 0000 \\
0 \cdot 1040 \\
0 \cdot 0000 \\
0 \cdot 0000 \\
0 \cdot 0000 \\
0 \cdot 0000 \\
\mathrm{n}=48\end{array}$ & 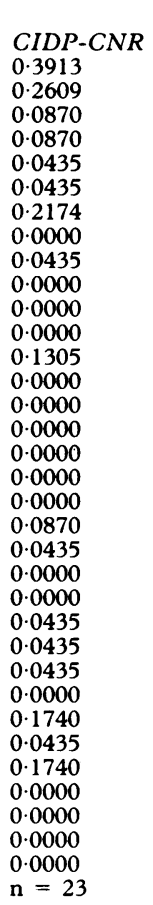 & $\begin{array}{l}\text { Controls } \\
0 \cdot 2679 \\
0.2691 \\
0.0366 \\
0.0783 \\
0.0731 \\
0.0870 \\
0.1343 \\
0.0203 \\
0.0262 \\
0.0330 \\
0.0095 \\
0.0000 \\
0.2893 \\
0.0123 \\
0.0000 \\
0.0103 \\
0.0000 \\
0.0207 \\
0.0155 \\
0.0765 \\
0.0251 \\
0.0014 \\
0.0001 \\
0.0208 \\
0.0186 \\
0.0701 \\
0.0175 \\
0.1085 \\
0.0175 \\
0.1165 \\
0.0024 \\
0.0009 \\
0.0006 \\
0.0000 \\
\mathrm{n}=2516\end{array}$ \\
\hline
\end{tabular}

pheral nervous system analogue of multiple sclerosis, ${ }^{3,12,13}$ it is interesting that the HLA antigen frequency changes seen in this study, though modest, are similar to those seen in some Caucasian patients with multiple sclerosis. Early studies in Northern Europe, the United States and later in Australia, reported an increased frequency of HLA - A3 and $-\mathrm{B} 7$ and decreased frequency of $-\mathrm{B} 12$ in Caucasians with MS. ${ }^{14-16}$

Table 2 Antigen frequencies

\begin{tabular}{|c|c|c|c|c|}
\hline $\begin{array}{l}H L A-D R, D R w, D Q L O C I \\
\text { Antigen }\end{array}$ & CIDP Total & $C I D P-C R$ & $C I D P-C N R$ & Controls \\
\hline $\begin{array}{l}\text { DR1 } \\
\text { DR2 } \\
\text { DR3 } \\
\text { DR4 } \\
\text { DR7 } \\
\text { DRw8 } \\
\text { DRw9 } \\
\text { DRw10 } \\
\text { DRw(11) } \\
\text { DRw12(5) } \\
\text { DRw13(w6) } \\
\text { DRw14(w6) } \\
\text { DRw52 } \\
\text { DRw53 } \\
\text { DQw1 } \\
\text { DQw2 } \\
\text { DQw3 }\end{array}$ & $\begin{array}{l}0.1607 \\
0.4107^{\mathrm{d}} \\
0 \cdot 3214 \\
0 \cdot 2321 \\
0 \cdot 1429^{\mathrm{g}} \\
0 \cdot 0357 \\
0 \cdot 0179 \\
0 \cdot 0000 \\
0 \cdot 0893 \\
0 \cdot 0000 \\
0 \cdot 2500 \\
0 \cdot 0179 \\
\mathrm{n}=56 \\
0 \cdot 5536 \\
0 \cdot 3929 \\
\mathrm{n}=56 \\
0.7140 \\
0.3929 \\
0 \cdot 4107 \\
\mathrm{n}=56\end{array}$ & $\begin{array}{l}0 \cdot 1579 \\
0 \cdot 4211^{\mathrm{e}} \\
0 \cdot 2895 \\
0 \cdot 2368 \\
0 \cdot 1579 \\
0 \cdot 0000 \\
0 \cdot 0263 \\
0 \cdot 0000 \\
0 \cdot 1316 \\
0 \cdot 0000 \\
0 \cdot 2105 \\
0 \cdot 0263 \\
\mathrm{n}=38 \\
0 \cdot 4474 \\
0 \cdot 4211 \\
\mathrm{n}=38 \\
0 \cdot 7368 \\
0 \cdot 3947 \\
0 \cdot 4474 \\
\mathrm{n}=38\end{array}$ & $\begin{array}{l}0 \cdot 1667 \\
0 \cdot 3889 \\
0 \cdot 3889^{1} \\
0 \cdot 2222 \\
0 \cdot 1111 \\
0 \cdot 1111 \\
0 \cdot 0000 \\
0 \cdot 0000 \\
0 \cdot 0000 \\
0 \cdot 0000 \\
0 \cdot 3333 \\
0 \cdot 0000 \\
n=18 \\
0 \cdot 7777 \\
0 \cdot 3333 \\
n=18 \\
0 \cdot 6667 \\
0 \cdot 3889 \\
0 \cdot 3333 \\
n=18\end{array}$ & $\begin{array}{l}0 \cdot 1730 \\
0 \cdot 2987 \\
0 \cdot 2892 \\
0 \cdot 3176 \\
0 \cdot 2552 \\
0 \cdot 0435 \\
0 \cdot 0123 \\
0 \cdot 0019 \\
0 \cdot 1115 \\
0 \cdot 0217 \\
0 \cdot 1957 \\
0 \cdot 0473 \\
\mathrm{n}=1058 \\
0 \cdot 6667 \\
0 \cdot 5841 \\
\mathrm{n}=315 \\
0 \cdot 6304 \\
0 \cdot 4627 \\
0 \cdot 5621 \\
\mathrm{n}=322\end{array}$ \\
\hline
\end{tabular}

$\mathrm{d}: \mathrm{p}=0.104 ; \mathrm{e}: \mathrm{p}=0.152 ; \mathrm{f}: \mathrm{p}=0.508 ; \mathrm{g}: \mathrm{p}=0.060$ 
Table 3 Co-occurrence of HLA Antigens

\begin{tabular}{lll}
\hline & CIDP & Controls $^{\star}$ \\
\hline Frequency of DR2 in B7 individuals & $80 \%$ & $48.3 \%$ \\
Frequency of B7 in DR2 individuals & $62 \%$ & $31.7 \%$ \\
\hline
\end{tabular}

^Ninth Histocompatibility Workshop 1984.

In the current study, both clinical subgroups of CIDP displayed a tendency for raised frequencies of HLA-B7 and -DR2 and decreased frequencies of HLA-44 (B12).

These results suggest that there may be genetic similarities between peripheral and central demyelinating disorders mapping to chromosome 6 genes, or linked genes. Involvement of common HLA alleles in CIDP and MS would support our earlier observation ${ }^{9}$ in the alpha-1-antitrypsin (Pi) system, but clearly, large multicentre studies are required to resolve this issue.

Alpha-1-antitrypsin genes are known to be in linkage with genes that code for constant regions of IgG heavy chains $(\mathrm{Gm}),{ }^{17}$ and in turn, these $\mathrm{Gm}$ genes interact with HLA genes to influence the immune response ${ }^{18}$ to disease. ${ }^{19-22}$ It is therefore appropriate to examine the possibility that HLA, $\mathrm{Pi}$ and $\mathrm{Gm}$ gene system interactions may be involved in CIDP and these studies are now planned.

This work was supported by grants from the National Health and Medical Research Council and the Multiple Sclerosis Society of Australia. DJ Feeney was partially supported by the Wenkart Foundation and was the holder of the Liston Wilson Fellowship at the University of Sydney during the tenure of this work.

1 Thomas PK, Lascelles RG, Hallpike JF, Hewer RI. Recurrent and chronic relapsing Guillain Barré polyneuritis. Brain 1969;92:589-606.

2 Asbury AK, Arnason BG, Adams RD. The inflammatory lesion in idiopathic polyneuritis. Medicine (Baltimore) 1969;48:173-215.

3 Prineas JW. Polyneuropathies of undetermined cause. Acta Neurol Scand 1970;46(Suppl 44):1-72.

4 Prineas JW, McLeod JG. Chronic relapsing polyneuritis. $J$ Neurol Sci 1976;27:427-58.

5 Stewart GJ, Pollard JD, McLeod JG, Wolnizer M. HLA antigens in the Landry-Guillain Barré syndrome and
chronic relapsing polyneuritis. Ann Neurol 1978;4:285-9.

6 Adams D, Festenstein H, Gibson JD, Hughes RAC,

Jaraquemada J, Papasteriadis C, Sachs J, Thomas PK. HLA antigens in chronic relapsing idiopathic inflammatory polyneuropathy. $J$ Neurol Neurosurg Psychiatry 1979;42:184-6.

7 Adams D, Gibson JD, Thomas PK, Batchelor JR, Hughes RAC, Kennedy L, Festenstein H, Sachs J. HLA antigens in Guillain Barré syndrome. Lancet 1977;22:504-5.

8 Winer JB, Briggs D, Welsh K, Hughes RAC. HLA antigens in the Guillain Barre syndrome. $J$ Neuroimmunol 1988; 18:13-6.

9 McCombe PA, Clark P, Frith JA, Hammond SR, Stewart GJ, Pollard JG, McLeod JG. Alpha-1-antitrypsin phenotypes in demyelinating disease and the allele PiM3. Ann Neurol 1985;18:514-6.

10 Feeney DJ, Pollard JD, McLeod JG, Stewart GJ, de Lange GG. Gm haplotypes in inflammatory demyelinating polyneuropathies. Ann Neurol (in press)

11 Dyck PJ, Lais AC, Bastron JA, Okazaki H, Groover RV. Chronic inflammatory polyradiculoneuropathy. Mayo Clinic Proc 1975;50:621-37.

12 McCombe PA, Pollard JD, McLeod JG. Chronic inflammatory demyelinating polyradiculoneuropathy. A clinical and electrophysiological study of 92 cases. Brain 1987; 110:1617-30.

13 Prineas JW. Demyelination and remyelination in recurrent idiopathic polyneuropathy. An electron microscope study. Acta Neuropath (Berl) 1971;18:34-57.

14 Naito S, Namerow N, Mickey M, Terasaki P. Multiple sclerosis: association with HL-A3. Tissue Ags 1972;2:1-4.

15 Bertrams J, Kuwert E Association of histocompatibility ham 1976;117:1906-12.

16 Alter M, Harshe M, Anderson V, Emme L, Yunis E. Genetic association of multiple sclerosis and HLA determinants. association of multiple scle

17 Gedde-Dahl T, Cook PJL, Fagerhol MK, Pierce JA. Improved estimate of the Gm-Pi linkage. Ann Hum Genet 1975;39:43-50

18 Whittingham S, Mathews JD, Schanfield MS, et al. Interactive effect of $\mathrm{Gm}$ allotypes and HLA B antigens on the human antibody response to a bacterial antigen. Clin Exp Immunol 1980;40:8-15.

19 Nakao Y, Matsumoto H, Miyazaki T, et al. Ig heavy chain allotypes $(\mathrm{Gm})$ in autoimmune diseases. Clin Exp Immunol 1981;42:20-6.

20 Whittingham S, Mathews JD, Schanfield MS, et al. Interaction of HLA and $\mathrm{Gm}$ in autoimmune chronic active tion of HLA and Gm in autoimmune

21 hepatitis. Clin Exp Immunol T, Matsumoto H. Two major genes linked to HLA and Gm control susceptibility to genes linked to HLA and $\mathrm{Gm}$ control

22 Feeney DJ. An investigation of major histocompatibility complex and $\mathrm{Gm}$ genetics in rheumatoid arthritis. Perth, Western Australia: University of Western Australia, 1982; pp34. (Thesis) 